\title{
EDUCAÇÃO VIRTUAL NAS UNIVERSIDADES: AS CONTRIBUIÇÕES DA APRENDIZAGEM COLABORATIVA
}

\author{
Patricia Lupion Torres ${ }^{1}$ \\ Pontifícia Universidade Católica do Paraná - PUCPR - Brasil \\ patorres@terra.com.br \\ Lilia María Marques Siqueira ${ }^{2}$ \\ Pontifícia Universidade Católica do Paraná - PUCPR - Brasil \\ lilia.siqueira@pucpr.br
}

Recepción: 04/09/2012

Evaluación: 29/09/2012

Aceptación: 15/11/2012

Artículo de Revisión

doi: http://dx.doi.org/10.9757/Rhela.19.08

\section{RESUMO}

Este estudo apresenta como hipótese central o fato de que a Universidade, dada a sua estrutura e a disponibilidade de recursos científicos e tecnológicos, é um lugar privilegiado para a criação e experimentação de propostas metodológicas para educação a distância. O presente artigo tem por objetivo apresentar a aprendizagem colaborativa como uma dessas propostas metodológicas, e as transformações nos papéis de alunos e de professores, quando aplicada em ambientes virtuais. Para a concretização deste estudo, realizou-se uma pesquisa bibliográfica, que reuniu informações sobre a evolução dos recursos tecnológicos, dados das universidades virtuais no mundo e no Brasil, levantamento dos modelos de EAD estruturados e em funcionamento no Brasil, conforme
Vianney e Torres (2010), Rama (2009), Silvio (2000). Realizou-se também uma breve revisão bibliográfica acerca dos conceitos de aprendizagem colaborativa e suas aplicações no contexto da universidade virtual, segundo Moran (2006), Siqueira (2003), Torres (2004) e Borba (2008); e conceitos de interatividade segundo Silva (2006). Como conclusão, sugere-se utilizar os pressupostos da aprendizagem colaborativa, a interatividade, a troca entre pares, e a flexibilização dos papéis nas comunicações e nas relações, como aspectos a considerar na concretização pedagógica da Universidade Virtual.

Palavras-chave: Revista História da Educação Latino-americana, ensino online, aprendizagem colaborativa, universidade virtual.

\footnotetext{
1 Doutora em Mídia e Conhecimento pela UFSC e Professora do Programa de Pós Graduação em Educação PPGE - Mestrado e Doutorado - PUCPR. Líder do Grupo de Pesquisa PRAPETEC - Prática Pedagógica no Ensino e Aprendizagem com Tecnologias Educacionais.

2 Doutora em Educação pela PUCPR e Coordenadora de Ensino a Distância da PUCPR, pesquisadora do Grupo de Pesquisa PRAPETEC - Prática Pedagógica no Ensino e Aprendizagem com Tecnologias Educacionais.
} 


\section{EDUCACIÓN VIRTUAL EN \\ UNIVERSIDADES: LAS CONTRIBUCIONES DE APRENDIZAJE COLABORATIVO}

\section{RESUMEN}

Este estudio tiene como el centro de hipótesis el hecho de que la universidad, por su estructura y la disponibilidad de los recursos científicos y tecnológicos, es un lugar privilegiado para la creación y experimentación de propuestas metodológicas para la educación a distancia. Este trabajo tiene como objetivo presentar un aprendizaje colaborativo como una de estas propuestas metodológicas y los cambios en los roles de los estudiantes y profesores, cuando se aplica a entornos virtuales. Para lograr este estudio, se realizó una búsqueda bibliográfica, que reunió información sobre la evolución de los recursos tecnológicos, los datos de las universidades de todo el mundo virtual y en Brasil, un estudio de los modelos de EAD estructurado y funcionando en Brasil, como Vianney y Torres (2010), Rama (2009), Silvio (2000). También se realizó una breve revisión bibliográfica sobre los conceptos de aprendizaje colaborativo y su aplicación en el contexto de la universidad virtual, de acuerdo con Moran (2006), Torres (2004), Siqueira (2003) y Borba (2008), y los conceptos de interactividad según Silva (2006). En conclusión, le sugerimos que utilice los supuestos del aprendizaje colaborativo, la interactividad, el intercambio entre pares, y la flexibilidad de los roles de las comunicaciones y relaciones, como aspectos a considerar en la implementación de la Universidad Virtual pedagógica.

Palabras clave: Revista Historia de la Educación Latinoamericana, aprendizaje en línea, aprendizaje colaborativo, la universidad virtual.

\section{VIRTUAL EDUCATION IN HIGHER EDUCATION INSTITUTIONS: CONTRIBUTION OF COLLABORATIVE LEARNING}

\begin{abstract}
This research has as central hypothesis a fact of Universities' capacity and structure, even its disposal of both scientific and technological resources due this is a priviledge space for creation and experimentation of methodological proposals for distance education. This research aimed for presenting a collaborative learning as a methodology proposal as well with a changing role for students and teachers, when applied to virtual environments. In order to accomplish this project's task, a previous bibliography research was run, this reviewed information on technological resources' evolution, Brazilian and worldwide universities data, a formal study on EAD models already appyed and worked in Brazil, in cases as Vianney and Torres (2010), Rama (2009), Silvio (2000).

A brief review on concepts of collaborative learning and its function on virtual university context. Accoring to Moran (2006), Torres (2004), Siqueira (2003) y Borba (2008), and interactivity concepts brought by Silva (2006). As a conclusion we suggest to use all pressumptions on collavorative learning, interactivity, learning Exchange and rol flexibility in communications and social relations in order to consider establishing a virtual pedagological University.
\end{abstract}

Key words: History of Latin American Education Journal, on line learning, collaborative learning, on line University.

\section{INTRODUÇÃO}

Com o aparecimento de uma nova sociedade globalizada e tecnificada aumenta a demanda por formação continua e aflora a necessidade de busca de novos modelos educacionais, capazes de responder às solicitações de formação profissional.

A educação neste início de século se desenvolve em uma sociedade na qual o conhecimento é a principal fonte de riqueza, produção e poder. 
Nesta sociedade do conhecimento, tem-se segundo Davies ${ }^{3}$ um prognóstico futuro de uma aprendizagem aberta, flexível e em tempo parcial, capaz de responder tanto as necessidades da economia, quanto as dos indivíduos, com um currículo baseado em competências e conhecimentos úteis, adquiridos em qualquer tempo ou lugar. Para este autor uma sociedade aberta, solicita sistemas educacionais igualmente abertos.

Buscando responder a estas demandas emergentes, as universidades vêm cada vez mais incorporando novas tecnologias nas situações de ensino aprendizagem. A rapidez com que a tecnologia se desenvolve e se insere em nossas vidas é uma característica do mundo atual. As universidades tem se beneficiado bastante das possibilidades oferecidas pelas tecnologias de informação e comunicação (TIC) e os processos educacionais influenciam e são influenciados pela evolução tecnológica. O desenvolvimento tecnológico se entrelaça as inovações pedagógicas, interferindo nos modelos educacionais e processos didáticos, promovendo uma virtualização e até uma hibridização dos espaços educacionais. A educação virtual é hoje uma modalidade consolidada que está disponível para auxiliar o aprimoramento continuado, tão exigido atualmente, democratizando o acesso a formação para um maior número de pessoas.

\section{Educação virtual ou educação online}

As oportunidades de acesso à informação vêm sendo incrementadas pelo uso das novas tecnologias de comunicação e pelo uso do computador. Milhões de pessoas estão conectadas à internet, formando redes de informações.

Isso só se tornou possível em função de determinados acontecimentos, entre os quais relacionamos alguns na breve cronologia apresentada a seguir ${ }^{4}$ :

David Davies, "Hacia una sociedad que aprende", in Organizaciones que aprenden y formación virtual, Eds. R Teare, D Davies y E. Sandelands (Barcelona: EDIUOC, 2002), 1.

Quadro apresentado por P.L Torres, em sua tese de titular baseado em diversos autores (2003). 


\section{Quadro 1. Evolução de Alguns Recursos Tecnológicos}

\begin{tabular}{|c|c|}
\hline CRONOLOGÍA & ACONTECIMENTOS \\
\hline 1642 & É creditado a Blaise Pacal a construção da primeira "máquina de calcular". \\
\hline 1671 & $\begin{array}{l}\text { Gottfried Wilhelm von Leibniz inventou um "computador" que foi construído } \\
\text { em 1694. Ele podia somar e, por meio de sucessivas somas e trocas podia também } \\
\text { multiplicar. }\end{array}$ \\
\hline 1820 & $\begin{array}{l}\text { Charles Xavier Thomas desenvolveu a primeira calculadora mecânica que podia } \\
\text { somar, subtrair, multiplicar, e dividir. }\end{array}$ \\
\hline 1822 & $\begin{array}{l}\text { Charles Babbage, professor de matemática começou a projetar e construiu um } \\
\text { pequeno modelo de demonstração da "máquina da diferença", uma máquina } \\
\text { calculadora mecânica automática. }\end{array}$ \\
\hline 1823 & $\begin{array}{l}\text { Com financiamento do governo britânico, Babbage, começou a construção de } \\
\text { uma máquina de diferença completa. }\end{array}$ \\
\hline 1833 & $\begin{array}{l}\text { Babbage começou a construção da "máquina analítica" que poderia hoje ser } \\
\text { chamado de um computador digital mecânico automático controlado por um } \\
\text { programa. }\end{array}$ \\
\hline 1854 & $\begin{array}{l}\text { George Boole publica trabalhos que serão a base lógica dos cálculos dos futuros } \\
\text { computadores. }\end{array}$ \\
\hline 1870 & $\begin{array}{l}\text { (aproximadamente em) Lorde Kelvin cria máquina analógica de prever marés, que } \\
\text { dará origem aos primeiros computadores analógicos. }\end{array}$ \\
\hline 1890 & $\begin{array}{l}\text { Herman Hollerith e James Powers desenvolveram dispositivos que poderiam ler } \\
\text { automaticamente a informação em cartões perfurados. }\end{array}$ \\
\hline 1901 & $\begin{array}{l}\text { Foi transmitido da Inglaterra ao Canadá, por Guglielmo Marconi, o primeiro sinal } \\
\text { de telegrafia sem fio. }\end{array}$ \\
\hline 1924 & Fundação da IBM, que fabrica perfuradores de cartões. \\
\hline 1941 & Konrad Zuse conclui o computador eletromagnético Z3. \\
\hline 1943 & $\begin{array}{l}\text { É concluído o Colossus, em Londres, primeiro computador digital específico para } \\
\text { quebrar códigos. }\end{array}$ \\
\hline 1944 & $\begin{array}{l}\text { Howard Hathaway Aiken, sua equipe e a da IBM concluem a máquina de Aiken, } \\
\text { chamada Harvard Mark I, o Marl I, computador eletromecânico, que funciona } \\
\text { com reles. }\end{array}$ \\
\hline 1946 & $\begin{array}{l}\text { É revelado ao público o ENIAC - "Integrador e Calculador Numérico Elétrico" } \\
\text { (Electrical Numerical Integrator And Calculator) o primeiro computador } \\
\text { totalmente eletrônico e digital desenvolvido em parceria pela Escola Moore da } \\
\text { Pensilvânia e pelo Laboratório de Pesquisas Balísticas do Exército Americano. }\end{array}$ \\
\hline 1947 & $\begin{array}{l}\text { Surge a primeira geração de computadores eletrônicos programados modernos } \\
\text { que usam memória de acesso aleatório (RAM). }\end{array}$ \\
\hline 1949 & $\begin{array}{l}\text { É concluído, na Universidade de Cambridge, o Edsac, o primeiro computador } \\
\text { digital que armazena o próprio programa. }\end{array}$ \\
\hline 1951 & É lançado o primeiro computador disponível comercialmente, o Univac-I. \\
\hline 1951 & É concluído o Edvac, computador eletrônico de variável discreta. \\
\hline 1952 & $\begin{array}{l}\text { O Instituto de Estudos Avançados da Universidade de Princeton, conclui seu } \\
\text { computado. }\end{array}$ \\
\hline
\end{tabular}




\begin{tabular}{|c|c|}
\hline 1953 & A IBM faz seu primeiro computador digital. \\
\hline 1957 & $\begin{array}{l}\text { É dado o primeiro passo rumo a sistemas "amigáveis" com o surgimento do } \\
\text { Fortran, linguagem que facilitou a programação de computadores. }\end{array}$ \\
\hline 1959 & Primeira máquina que ficou conhecida como minicomputador - o PDP. \\
\hline $1950-59$ & $\begin{array}{l}\text { Na década de } 1950 \text { é criado nos Estados Unidos o Advanced Research Projects } \\
\text { Agency - ARPA, para desenvolver alta tecnologia para as forcas armadas. }\end{array}$ \\
\hline 1960 & $\begin{array}{l}\text { É desenvolvido o Cobol, primeira linguagem orientada para a programação } \\
\text { comercial. }\end{array}$ \\
\hline 1961-68 & $\begin{array}{l}\text { São definidos os padrões para uma rede Packed Switch, uma rede de pacotes } \\
\text { comutados. }\end{array}$ \\
\hline 1962 & $\begin{array}{l}\text { É apresentado nos EUA o projeto de uma grande rede de comunicações e } \\
\text { trabalhos em grupo. }\end{array}$ \\
\hline 1969 & $\begin{array}{l}\text { É desenvolvido nos Laboratórios Bell o sistema Unix, que originou a linguagem } \\
\text { de programação C. }\end{array}$ \\
\hline 1969 & $\begin{array}{l}\text { Foi criada a ARPANET, responsável pelo desenvolvimento da rede que se } \\
\text { transformou na Internet. }\end{array}$ \\
\hline 1970 & $\begin{array}{l}\text { É feita a primeira conexão entre a UCLA na Califórnia com a BBN em } \\
\text { Massachussets, com um link de } 56 \text { Kbps. }\end{array}$ \\
\hline 1971 & Intel 4004, primeiro microprocessador disponível comercialmente. \\
\hline $1971-80$ & Diversas empresas desenvolvem e apresentam seus computadores pessoais. \\
\hline 1971 & $\begin{array}{l}\text { Ray Tomlinson, funcionário da BBN, inventa o e-mail, para comunicação interna } \\
\text { da instituição. }\end{array}$ \\
\hline 1972 & $\begin{array}{l}\text { Ray Tomlinson, altera o programa de e-mail, para que possa ser usado por todos } \\
\text { da ARPANET. Decide usar o símbolo @ para definir em qual servidor deve ser } \\
\text { encontrado o destinatário. }\end{array}$ \\
\hline 1973 & $\begin{array}{l}\text { Primeiros servidores europeus se ligam a ARPANET. São feitas conexões com a } \\
\text { University College of London (Inglaterra) e a Norsar (Noruega). }\end{array}$ \\
\hline 1974 & $\begin{array}{l}\text { Inicia-se o desenvolvimento da rede, com o TC/IP um protocolo que permite a } \\
\text { interligação de diferentes redes, máquinas e sistemas operacionais. }\end{array}$ \\
\hline 1974 & $\begin{array}{l}\text { A BBN lança o primeiro serviço privado de dados, a TELNET, uma versão } \\
\text { comercial da ARPANET. }\end{array}$ \\
\hline 1979 & $\begin{array}{l}\text { São criados os primeiros Grupos de Discussão (Newsgroups) usando o UUCP, } \\
\text { surge o USENET. }\end{array}$ \\
\hline 1981 & Lançamento do IBM-PC primeiro computador pessoal vendido com sucesso. \\
\hline 1983 & $\begin{array}{l}\text { Acontece a divisão da ARPANET em: ARPANET e MILNET (rede Militar). Dos } \\
113 \text { nós existentes na rede, } 68 \text { foram para administração dos militares. }\end{array}$ \\
\hline 1984 & $\begin{array}{l}\text { Com a criação da JUNET (Japan Unix Network), que usa UUCP para se interligar } \\
\text { a rede, o Japão passa a integrar a rede. }\end{array}$ \\
\hline 1986 & $\begin{array}{l}\text { É criada a NSFNET - National Science Foundation (Fundação Nacional para } \\
\text { Ciência), que recebe a missão de transformar a ARPANET em Internet. }\end{array}$ \\
\hline 1987 & Com a abertura para fins comerciais a rede passa a crescer. \\
\hline 1989 & $\begin{array}{l}\text { São feitos os primeiros testes de e-mail fora do meio acadêmico, entre empresas } \\
\text { comerciais. }\end{array}$ \\
\hline
\end{tabular}




\begin{tabular}{|c|l|}
\hline 1989 & $\begin{array}{l}\text { Outros países se conectam à Internet, entre eles Austrália, Alemanha, Israel, } \\
\text { Japão, México, Nova Zelândia, Porto Rico e Reino. }\end{array}$ \\
\hline 1990 & $\begin{array}{l}\text { A ARPANET é fechada, mas a rede militar ainda continua, sob a administração } \\
\text { da MILNET. }\end{array}$ \\
\hline 1990 & $\begin{array}{l}\text { Novos países se conectam a rede, são eles: Brasil, Argentina, Chile, Áustria, } \\
\text { Bélgica, Grécia, Irlanda, Espanha, Suíça, Índia e Coréia. }\end{array}$ \\
\hline 1991 & $\begin{array}{l}\text { Paul Lindner e Mark P. McCahill, da Universidade de Minnesota, desenvolvem o } \\
\text { GOPHER, primeiro mecanismo de pesquisa para a Internet. }\end{array}$ \\
\hline 1991 & Criação da World Wide Web. \\
\hline
\end{tabular}

Como se pode observar no quadro acima, em diversos momentos o desenvolvimento tecnológico se entrelaça a processos educacionais, interferindonos mesmos. Da mesma forma, a educação à distância após a amplificação do uso educacional de tecnologias de comunicação e informação sofreu uma mudança substancial transformando-se em educação a distância virtual ou simplesmente educação virtual. A ideia de uma Universidade Virtual não é nova, tendo surgido na década de 1980 com a criação, em 1983, da University of the World (UW) e o estabelecimento de sua sede na Califórnia. A Universidade almejava utilizar a rede BITNET-EARN ${ }^{5}$, mas esta rede não teve força, abertura e flexibilidade suficientes sendo superada pela Internet. Esta Universidade nunca chegou de fato a ser implantada e por volta de 1991 os possíveis membros que a constituiriam deixaram de se reunir ${ }^{6}$.

Tim Berners-Lee, entre 1989 e 1991, desenvolveu no Laboratório de Física de Partículas, em Genebra, um protocolo Europeu denominado de World Wide Web, fato determinante para o avanço da educação virtual. No início apenas uns poucos pesquisadores do mundo utilizavam a Web, até que em 1993, a Universidade de Illinois liberou para o uso, gratuitamente, o Mosaic, um visor de Web de fácil utilização. Nesse mesmo período existiam mais de 15 projetos com propósitos semelhantes aos da University of the World UW, entre os quais destaca-se a Global University System (http://www.solar.rtd.utk.edu/GLOSAS/global_University) criada em 1991, em Nova York, que permanece em funcionamento até hoje, mais como um espaço de cooperação entre universidades e acadêmicos do que

\footnotetext{
5 Rede Acadêmica antecessora da Internet, que chegou a agrupar 3500 universidades e centros de investigação de aproximadamente 50 países ao redor do mundo. José Silvio, La virtualización de la universidad (Caracas: IESALC, 2000), 307-310.

$6 \quad$ Silvio, La virtualización, 307-310.
} 
como uma instituição de graduação e diplomação ${ }^{7}$. A universidade virtual é uma decorrência da era da informação, sendo assim, um sistema baseado em equipamentos de informática, telefonia e internet. Ela conglomera um espaço eletrônico e possui possibilidades infinitas de interação ${ }^{8}$.

As características de comunicação incorporadas pelas novas gerações também tem modificado sobremaneira a forma de estudar dos alunos. A comunidade universitária é composta por usuários de novas mídias em seu cotidiano. Muitos estudantes são "nativos digitais", termo cunhado por Marc Prensky9 em 2001, que faz referência aos nascidos pós 1980, que fazem uso diariamente em seu contexto familiar e educacional, de meios digitais e mídias convergentes. Estes estudantes também participam de diversas redes de relacionamento virtuais. São pessoas mais habituadas a esses meios e que como consequência desenvolveram novas formas de se relacionar com os conteúdos a serem apreendidos por eles. A somatória destes fatores tem gerado maior interação e colaboração nos trabalhos dos estudantes. Em outra obra, Prensky ${ }^{10}$, assinala que o grande desafio para os professores será preparar estudantes, já nascidos no século XXI, para serem cidadãos e profissionais que falam menos e pensam mais. Enfatiza ainda que é necessário pensar em longo prazo, e este planejamento deve ultrapassar a organização escolar, avançando para a atualização na legislação educativa.

Observa-se que a tecnologia oferece meios que facilitam o processo de cooperação, seja ele educativo, seja do campo laboral, pois além da relação entre sujeitos é acrescida a possibilidade de cooperação entre eles e as entidades de software (os agentes), transformados em elementos facilitadores do processo de comunicação e aprendizagem em comunidades virtuais de grande porte ${ }^{11}$. O quadro 2 apresenta alguns dados da Educação Virtual em universidades ao redor do mundo, baseado em Silvio $(2000)^{12}$ com a atualização das informações levantadas nos sites das instituições selecionadas.

Silvio, La virtualización, 311.

Arnaldo Niskier, Educação à distância: a tecnologia da esperança (São Paulo: Loyola, 2000), 63.

Marc Prensky, "Digital Natives, Digital Immigrants", On the Horizon, Vol. 9 No. 5, (2001), 1-6.

Prensky ressalta: "Isto requer completa integração entre ensinar e habilidades como pensamento crítico, resolução de problemas, linguagem de programação, da mesma forma que hoje integramos ler e escrever." Prensky, "Digital Natives", 3.

11 P. C Cunha Filho et al., educação à distância no Brasil na era da Internet - O Projeto Virtus e a Construção de Ambientes Virtuais de Estudo Cooperativo (São Paulo: Anhembi Morumbi, 2000),63.

12 Silvio, La virtualización, 315-366. 


\section{Quadro 2 - Universidades Virtuais}

\begin{tabular}{|c|c|c|}
\hline UNIVERSIDADE & PAÍS & DESCRIÇÃO \\
\hline $\begin{array}{l}\text { UNIVERSIDAD } \\
\text { NACIONAL DE } \\
\text { EDUCACIÓN A } \\
\text { DISTANCIA }\end{array}$ & Espanha & $\begin{array}{l}\text { A UNED tem uma ampla oferta em educação de } \\
\text { nível superior a distância ( } 27 \text { graduações, } 53 \text { cursos } \\
\text { de mestrado, } 44 \text { programas de doutorado), além de } \\
\text { cursos de educação continuada com mais de } 600 \\
\text { cursos de certificação. (http://portal.uned.es) }\end{array}$ \\
\hline $\begin{array}{l}\text { UNIVERSITAT } \\
\text { OBERTA DE } \\
\text { CATALUNYA - UOC }\end{array}$ & Espanha & $\begin{array}{l}\text { Inaugurada em } 1995 \text {, é uma universidade que já nasceu } \\
\text { com a proposta do ensino à distância. Apresenta } \\
\text { método de aprendizagem embasada em quatro } \\
\text { princípios: flexibilidade, personalização, interatividade } \\
\text { e cooperação. } \\
\text { (http://www.uoc.edu) }\end{array}$ \\
\hline EUROPACE & Diversos & $\begin{array}{l}\text { A Europace é uma associação sem fins lucrativos, } \\
\text { formada por Instituições de Ensino Superior, ONGS } \\
\text { e Instituições Empresariais. Tem como objetivo } \\
\text { principal o desenvolvimento da rede e-learning, } \\
\text { para a mobilidade virtual, para a internacionalização } \\
\text { do ensino superior, para a criação e partilha de } \\
\text { conhecimento, e para a aprendizagem ao longo da } \\
\text { vida. (http://www.europace.org) }\end{array}$ \\
\hline $\begin{array}{l}\text { AFRICAN VIRTUAL } \\
\text { UNIVERSITY - AVU }\end{array}$ & Diversos & $\begin{array}{l}\text { A UVA oferece três tipos de cursos: online, misto, } \\
\text { presencial. Os cursos on-line são entregues 100\% } \\
\text { via web, através das salas de aula virtuais AVU. Os } \\
\text { cursos mistos possuem uma parte presencial, e são } \\
\text { modalidades projetadas para cursos que requerem } \\
\text { uma parte prática. Os cursos totalmente presenciais } \\
\text { são ministrados através das instituições parceiras. } \\
\text { (http://www.avu.org/) }\end{array}$ \\
\hline $\begin{array}{l}\text { UNIVERSITY OF } \\
\text { SOUTH AFRICA - } \\
\text { UNISA }\end{array}$ & Africa do Sul & $\begin{array}{l}\text { A UNISA é uma instituição de ensino a distância } \\
\text { que surgiu, oficialmente, em Janeiro de } 2004 \text { através } \\
\text { de uma fusão entre a University of South Africa, a } \\
\text { Technikon Southern Africa e a Vista University } \\
\text { Distance Educacion Campus (Vudec). (http://www. } \\
\text { unisa.ac.za/) }\end{array}$ \\
\hline $\begin{array}{l}\text { UNIVERSIDAD } \\
\text { TEC VIRTUAL } \\
\text { DEL SISTEMA } \\
\text { TECNOLÓGICO DE } \\
\text { MONTERREY }\end{array}$ & México & $\begin{array}{l}\text { Criada em 1996, a universidade virtual opera por } \\
\text { meio de tecnologias de telecomunicações e redes } \\
\text { eletrônicas. Possui centros colaborativos, em que } \\
\text { professores e alunos desenvolvem projetos, estudos } \\
\text { de casos, simulações e discutem os conteúdos do } \\
\text { curso. Está presente em } 22 \text { países da América, além } \\
\text { de Espanha e Portugal. (http://www.ruv.itesm.mx/) }\end{array}$ \\
\hline
\end{tabular}




\begin{tabular}{|c|c|c|}
\hline $\begin{array}{l}\text { UNIVERSIDAD } \\
\text { LATINOAMERICANA }\end{array}$ & México & $\begin{array}{l}\text { Universidade que iniciou suas atividades em 1976. Em } \\
\text { agosto de } 2008 \text { se uniu a Apollo Global, um grupo } \\
\text { internacional que conta com faculdades de prestígio } \\
\text { entre os seus membros. Em 2011, lançou o conceito } \\
\text { ULA flexível, oferecendo cursos com programação } \\
\text { mista, sendo uma pequena parte presencial e a } \\
\text { maior parte no ambiente virtual. Esse programa } \\
\text { está intitulado como Licenciaturas e Mestrados para } \\
\text { Executivos. (http://www.ula.edu.mx/) }\end{array}$ \\
\hline $\begin{array}{l}\text { ANADOLU } \\
\text { UNIVERSITY - AU }\end{array}$ & Turquia & $\begin{array}{l}\text { Universidade em funcionamento desde 1982, que } \\
\text { nasceu como uma instituição de ensino à distância. } \\
\text { Sua atuação era por meio das mídias tradicionais. } \\
\text { Hoje, oferece } 12 \text { graduações e } 46 \text { pós-graduações } \\
\text { com um sistema de educação a distância composto } \\
\text { por livros, programas de televisão, aconselhamento } \\
\text { acadêmico, e-learning e videoconferência. (http:// } \\
\text { www.anadolu.edu.tr) }\end{array}$ \\
\hline $\begin{array}{l}\text { INDIRA GHANDI } \\
\text { NATIONAL OPEN } \\
\text { UNIVERSITY - IGNOU }\end{array}$ & Índia & $\begin{array}{l}\text { Criada pelo parlamento Indu em 1985, começa a atuar } \\
\text { em 1987. Com o lançamento do EDUSAT (um satélite } \\
\text { dedicado apenas à educação) em } 20 \text { de setembro de } \\
\text { 2004, e a criação do Consórcio Inter-Universitário, a } \\
\text { Universidade deu início a uma nova era da tecnologia } \\
\text { voltada para a educação no país. Hoje, é reconhecida } \\
\text { como líder mundial em educação a distância, com } \\
\text { prêmios de excelência pela Commonwealth of } \\
\text { Learning (COL), no Canadá. Em janeiro de } 2010 \text {, } \\
\text { foi listada em } 12{ }^{\circ} \text { no ranking webométricos de } \\
\text { universidades indianas, com base no calibre de sua } \\
\text { presença na Internet. (http://www.ignou.ac.in/) }\end{array}$ \\
\hline $\begin{array}{l}\text { UNIVERSITAS } \\
\text { TERBUKA -UT }\end{array}$ & Tailândia & $\begin{array}{l}\text { Foi criada por um decreto presidencial em setembro } \\
\text { de1984. A UT funciona através do ensino à distância, } \\
\text { com uso dos meios de comunicação impressos } \\
\text { (módulos) e virtuais (áudio, vídeos, internet, rádio e } \\
\text { televisão). Tem quatro faculdades e um programa de } \\
\text { pós-graduação que oferece mais de } 30 \text { cursos com } \\
\text { diferentes níveis de cobertura. (http://www.ut.ac.id/) }\end{array}$ \\
\hline $\begin{array}{l}\text { OPEN LEARNING } \\
\text { AGENCY }\end{array}$ & Austrália & $\begin{array}{l}\text { Empresa privada que congrega } 20 \text { importantes } \\
\text { universidades e outros estabelecimentos de ensino } \\
\text { ao redor da Austrália. São ofertadas mais de } 170 \\
\text { qualificações online. (http://www.open.edu.au/) }\end{array}$ \\
\hline $\begin{array}{l}\text { DEAKIN UNIVERSITY } \\
\text { DE AUSTRALIA }\end{array}$ & Austrália & $\begin{array}{l}\text { Oferece vários cursos na modalidade off-campus } \\
\text { study. Neste modelo, os alunos que estudam fora do } \\
\text { campus, por meio da educação à distância, recebem } \\
\text { a mesma orientação dos estudantes do campus. São } \\
\text { providos por métodos de estudo bem completos, } \\
\text { incluindo modelos interativos como a conferência on- } \\
\text { line. (http://www.deakin.edu.au/) }\end{array}$ \\
\hline
\end{tabular}




\begin{tabular}{|c|c|c|}
\hline OPEN POLYTECHNIC & $\begin{array}{l}\text { Nova } \\
\text { Zelândia }\end{array}$ & $\begin{array}{l}\text { A Open polytechnic é de propriedade do governo da } \\
\text { Nova Zelândia. Oferece cursos á distância a todo o seu } \\
\text { país e também internacionalmente. Há envolvimento } \\
\text { da indústria no desenvolvimento da maioria dos } \\
\text { cursos. São mais de } 100 \text { qualificações } 1200 \text { cursos de } \\
\text { diversos níveis. (http://www.openpolytechnic.ac.nz/) }\end{array}$ \\
\hline edX & EUA & $\begin{array}{l}\text { edX é uma empresa sem fins lucrativos fundada } \\
\text { pela Universidade de Harvard e pelo Instituto de } \\
\text { Tecnologia de Massachusetts com o intuito de oferecer } \\
\text { cursos/estudos on-line. Junto com a oferta de cursos } \\
\text { on-line, as instituições usarão o edX para pesquisar } \\
\text { como os alunos aprendem e como a tecnologia pode } \\
\text { transformar a aprendizagem. (https://www.edx.org/) }\end{array}$ \\
\hline $\begin{array}{l}\text { Jones Internacional } \\
\text { University - JIU }\end{array}$ & EUA & $\begin{array}{l}\text { Criada em 1995, tem seus setores administrativos } \\
\text { em Englewood, Colorado, USA. Trata-se de uma } \\
\text { universidade totalmente virtual, privada, sem fins } \\
\text { lucrativos, que tem comoobjetivo "tornarmais acessível } \\
\text { e sustentável o aprendizado interativo para adultos } \\
\text { motivados em nível mundial, entregando conteúdos } \\
\text { por meios eletrônicos " A JIU oferece variados } \\
\text { programas que fornecem ferramentas e estratégias } \\
\text { essenciais para começar ou avançar na carreira. A } \\
\text { evolução dos estudantes, suas necessidades pessoais e } \\
\text { acadêmicas estão no centro das políticas, plataformas } \\
\text { de aprendizagem e serviços da instituição. http:// } \\
\text { www.jiu.edu/ }\end{array}$ \\
\hline $\begin{array}{l}\text { Western Governors } \\
\text { University - WGU }\end{array}$ & EUA & $\begin{array}{l}\text { Foi criada em 1995, por uma associação de } 19 \\
\text { estados do oeste dos Estados Unidos e tem seus } \\
\text { setores administrativos em Utah. Trata-se de uma } \\
\text { rede, com funcionamento autônomo, apoiada } \\
\text { por mais de } 20 \text { grandes empresas e fundações } \\
\text { que acreditam no compromisso WGU para } \\
\text { produzir graduados altamente competentes. } \\
\text { É composta por } 46 \text { instituições superiores, entre } \\
\text { as quais se encontram universidades e colégios } \\
\text { comunitários. A Western Governors University } \\
\text { é uma universidade online impulsionada pela } \\
\text { missão de expandir o acesso ao ensino superior } \\
\text { por meio de programas on-line. A WGU é uma } \\
\text { universidade nacional, que atende a mais de } 30.000 \\
\text { estudantes de todos os } 50 \text { estados americanos. } \\
\text { (www.wgu.edu/wgu/index.html). }\end{array}$ \\
\hline
\end{tabular}




\begin{tabular}{|c|c|c|}
\hline $\begin{array}{l}\text { University of Phoenix } \\
\text { Online - UP }\end{array}$ & EUA & $\begin{array}{l}\text { Criada em 1989, faz parte da Universidade de Phoenix } \\
\text { territorial, embora a extensão virtual seja autônoma. } \\
\text { Seus estudantes podem fazer cursos totalmente } \\
\text { virtuais e cursos combinados presenciais/virtuais. } \\
\text { Atende estudantes de } 21 \text { países, além dos americanos } \\
\text { Este ano, a Universidade comemora seu } 20^{\circ} \text { ano de } \\
\text { ensino on-line, com os alunos de todos os continentes } \\
\text { do mundo. A Universidade de Phoenix utiliza-se do } \\
\text { poder das tecnologias digitais para ajudar os alunos } \\
\text { a desenvolvere habilidades e competências mais } \\
\text { demandadas no mundo do trabalho. } \\
\text { (online.uophx.edu/Default.asp). }\end{array}$ \\
\hline $\begin{array}{l}\text { Califórnia Virtual Campus } \\
\text { - CVC }\end{array}$ & EUA & $\begin{array}{l}\text { A Califórnia é um dos estados do oeste americano } \\
\text { que não se integrou a WGU, optando por criar, } \\
\text { também por iniciativa governamental, a California } \\
\text { Virtual Campus - CVC, um consórcio de } 111 \\
\text { instituições que reúne } 67 \text { Colégios Comunitários, } 18 \\
\text { colégios e universidades independentes do Estado, } 19 \\
\text { Campus da Califórnia State University e } 7 \text { Campus } \\
\text { da University of Califórnia. Sua função é a de } \\
\text { intermediar o acesso dos alunos aos programas das } \\
\text { instituições que compõem o consórcio. A Califórnia } \\
\text { Campus Virtual tem parceria com MyEdu para } \\
\text { fornecer informações sobre os cursos e horários das } \\
\text { aulas de todas as instituições que compõem a CVC, } \\
\text { além de auxiliar a gerenciar o cronograma, a equilibrar } \\
\text { a carga de trabalho, e a comparar os preços de livros } \\
\text { didáticos. Possui mais de } 19.000 \text { cursos e } 1.100 \text { cursos } \\
\text { de pós graduação oferecidos em suas } 170 \text { instituições } \\
\text { credenciadas de ensino superior. (www.cvc.edu). }\end{array}$ \\
\hline $\begin{array}{l}\text { New York Institute of } \\
\text { Technology - NYIT }\end{array}$ & EUA & $\begin{array}{l}\text { Trata-se de uma extensão virtual de uma universidade } \\
\text { territorial. Por meio de um campus virtual são ofertados } \\
\text { cursos totalmente onlinee cursosparcialmente online. São } \\
\text { desenvolvidas atividades de apoio ao ensino presencial. } \\
\text { A New York Institute of Technology (NYIT) foi } \\
\text { fundada em } 1955 \text { por uma equipe de visionários que } \\
\text { queriam abrir novos caminhos no ensino superior. } \\
\text { Eles acreditavam que poderia haver um equilíbrio } \\
\text { entre a formação profissional e educação em artes } \\
\text { liberais. Atualmente a NYIT atua globalmente } \\
\text { trazendo tecnologia de infusão de educação } \\
\text { profissional, para os estudantes em vários continentes. } \\
\text { A NYIT é credenciada pelo Middle States Commission } \\
\text { on Higher Education. A Middle States Commission } \\
\text { on Higher Education, é uma agência de acreditação } \\
\text { institucional reconhecida pela Secretaria de Educação } \\
\text { dos EUA e do Conselho de Acreditação do Ensino } \\
\text { Superior. (www.nyit.edu). }\end{array}$ \\
\hline
\end{tabular}




\begin{tabular}{|c|c|c|}
\hline $\begin{array}{l}\text { New Jersey Institute of } \\
\text { Technology - NJIT }\end{array}$ & EUA & $\begin{array}{l}\text { Também se trata de uma extensão virtual de uma } \\
\text { universidade territorial, que sedestacoupordesenvolver } \\
\text { um sistema de comunicação multissíncrono. A NJIT } \\
\text { oferece um ensino online de alcance mundial. O } \\
\text { material pode ser acessado via internet, CDROM e } \\
\text { DVD o que facilita o aprendizado. (www.njit.edu/dl). }\end{array}$ \\
\hline $\begin{array}{l}\text { Nacional Technological } \\
\text { University - NTU }\end{array}$ & EUA & $\begin{array}{l}\text { Atua como intermediária para facilitar aos alunos o } \\
\text { acesso a } 48 \text { instituições filiadas. Utiliza-se de tecnologias } \\
\text { associadas, tais quais: ensino por videoconferência via } \\
\text { satélite e aprendizagem por meio da WEB (www.ntu. } \\
\text { edu). } \\
\text { A Laureate Education comprou a instituição e a partir } \\
\text { de } 2011 \text { a NTU não está mais aceitando novos alunos } \\
\text { somente atendendo as necessidades doa alunos já } \\
\text { matriculados. }\end{array}$ \\
\hline Walden University & EUA & $\begin{array}{l}\text { Desde } 1970 \text { oferece educação a distância. Atualmente } \\
\text { esta abrangente universidade online, credenciada pela } \\
\text { Comissão de Ensino Superior e membro da North } \\
\text { Central Association, oferece mestrado e doutorado em } \\
\text { educação, psicologia, saúde, gestão e serviços humanos. } \\
\text { (www.waldenuniversity.com) }\end{array}$ \\
\hline $\begin{array}{l}\text { Nova Southeastern } \\
\text { University -NSU }\end{array}$ & EUA & $\begin{array}{l}\text { Universidade do estado da Flórida, desenvolve alguns } \\
\text { programas a distância. Os alunos da educação a distância } \\
\text { tem acesso a serviços de apoio como a biblioteca } \\
\text { eletrônica, internet e software para computador. } \\
\text { (http://itde.nova.edu/itde/newindex.html). }\end{array}$ \\
\hline $\begin{array}{l}\text { Tele Université du Quebec } \\
\text { - TELUQ }\end{array}$ & Canadá & $\begin{array}{l}\text { É a primeira universidade totalmente a distância } \\
\text { em Quebec. Desde sua criação em } 1972 \text { expandiu } \\
\text { sua gama que agora inclui mais de } 400 \text { cursos e } 75 \\
\text { programas em todos os níveis de ensino. Registra até } \\
\text { o momento mais de um milhão de alunos.(www.teluq. } \\
\text { uquebec.ca/webteluq/index.html) }\end{array}$ \\
\hline Athabasca University & Canadá & $\begin{array}{l}\text { Universidade com grande experiência em EAD, } \\
\text { no início dos anos } 2000 \text { passou por um processo } \\
\text { de transição para a virtualização, iniciado com um } \\
\text { projeto denominado Virtual Teaching and Learning - } \\
\text { VITAL O "Centre for Athabasca University's Master } \\
\text { of Education in Distance Education (MEd)" é um } \\
\text { dos programas mais antigos em educação a distância. } \\
\text { Oferece mais de } 750 \text { cursos em uma ampla gama de } \\
\text { assuntos. Os cursos são projetados para estudo on- } \\
\text { line, à distância, ou em uma sala de aula para que o } \\
\text { aluno possa continuar a sua educação, sem sacrificar } \\
\text { a carreira, os compromissos pessoais e familiares. } \\
\text { Assim a proposta da Universidade ajuda os alunos a } \\
\text { superarem as barreiras de espaço e tempo. As taxas de } \\
\text { curso incluem todos os livros didáticos e materiais, de } \\
\text { modo que o discente conhece o investimento desde o } \\
\text { início. (www.athabascau.ca/). }\end{array}$ \\
\hline
\end{tabular}




\begin{tabular}{|c|c|c|}
\hline $\begin{array}{l}\text { British Columbia Open } \\
\text { University University }\end{array}$ & Canadá & $\begin{array}{l}\text { Faz parte da Open Learning Agency (www.ola.bc.ca/) } \\
\text { do Canadá. Expandiu o campus da UBC para todo } \\
\text { o mundo oferecendo mais de } 120 \text { cursos a distância. } \\
\text { (www.ola.bc.ca/bcou). }\end{array}$ \\
\hline Open University - OU & Reino Unido & $\begin{array}{l}\text { Uma das mais tradicionais universidades de educação } \\
\text { a distância, desde seu início tem buscado de maneira } \\
\text { progressiva incorporar novas tecnologias mantendo } \\
\text { a coerência pedagógica. O sistema "Open Learning", } \\
\text { utilizado é para o aluno estudar onde desejar. É } \\
\text { possível ler, assistir e ouvir o material fornecido além } \\
\text { de ainda contar com o apoio de um tutor. Os alunos } \\
\text { podem interagir entre si por meio do sistema da UO } \\
\text { de conferência online, tutoriais e grupos de estudo } \\
\text { informais.(www.open.ac.uk). }\end{array}$ \\
\hline $\begin{array}{l}\text { Centre National d' } \\
\text { Enseignement á Distance } \\
\text { - CNED }\end{array}$ & França & $\begin{array}{l}\text { Considerado uma instituição de educação superior, } \\
\text { embora trabalhe com todos os níveis de ensino. } \\
\text { Em } 1997 \text { cria um campus eletrônico, acessível por } \\
\text { telefone, televisão e rede telemática. É uma instituição } \\
\text { de natureza pública, sob a supervisão dos Ministérios } \\
\text { da Educação e Ensino Superior e Pesquisa. (www. } \\
\text { cned.fr). }\end{array}$ \\
\hline $\begin{array}{l}\text { Federation } \\
\text { Interuniversitaire } \\
\text { d'Enseignement a Distance }\end{array}$ & França & $\begin{array}{l}\text { Composta por } 16 \text { universidades, de } 14 \text { países da } \\
\text { Europa, esta rede foi criada em 1987. Oferece a seus } \\
\text { membros serviços de correio eletrônico, biblioteca } \\
\text { virtual e formações atualizadas de seus programas. Não } \\
\text { é necessário residir próximo a escola, embora possam } \\
\text { ocorrer momentos presenciais para consolidação e } \\
\text { revisão de conteúdos. (www.telesup.univ } \sim \text { mrs.fr/ } \\
\text { TELESUP/LaFIED). }\end{array}$ \\
\hline $\begin{array}{l}\text { Conservatoire Nacional d ‘ } \\
\text { Arts et Métiers - CNAM }\end{array}$ & França & $\begin{array}{l}\text { Instituição de Ensino e Pesquisa, tem como missão } \\
\text { a formação continuada e a formação para o trabalho. } \\
\text { O ensino está estruturado com base em mídias } \\
\text { integradas, entre as quais a Internet (web.cnam.fr/). }\end{array}$ \\
\hline $\begin{array}{l}\text { NETwork per l' Universita } \\
\text { Ovunque - NETTUNO }\end{array}$ & Itália & $\begin{array}{l}\text { É uma organização sem fins lucrativos promovida pelo } \\
\text { Ministério da Educação, Universidade e Pesquisa. A } \\
\text { rede utiliza-se de telemática, áudio e videoconferência } \\
\text { via satélite, televisão pública, vídeo e internet. } \\
\text { (http://www.consorzionettuno.it/nettuno/brochure/ } \\
\text { eng.htm) }\end{array}$ \\
\hline FernUniversität & Alemanha & $\begin{array}{l}\text { Tradicional universidade de educação a distância, } \\
\text { desde seu início tem buscado incorporar o que há } \\
\text { de mais moderno em tecnologia integrando novos } \\
\text { modelos pedagógicos a EAD. Oferece diversos cursos } \\
\text { em áreas diversas http://www.fernuni-hagen.de/). }\end{array}$ \\
\hline
\end{tabular}

Conforme constata-se no quadro 2, a educação virtual vem se estruturando a partir dos anos noventa e encontra-se consolidada nas grandes universidade do mundo. A universidade virtual caracteriza-se principalmente pelo 
uso de tecnologias interativas - como a internet e a videoconferência - e prioriza o processo de comunicação.

\section{Breves excertos sobre a universidade virtual no Brasil}

A expansão das matrículas, a entrada de novos fornecedores locais, o aumento da regulamentação governamental, a diferenciação institucional, a mercantilização, a internacionalização e a virtualização, caracterizam a metamorfose que ocorre na América Latina e no Caribe nos sistemas de ensino superior à distância. ${ }^{13}$

Neste cenário, o Brasil apresenta-se como o país que alcançou o maior crescimento na região ${ }^{14}$. Esta dinâmica deriva da mudança da legislação educacional brasileira ${ }^{15}$ e do investimento de algumas universidades presenciais que, na década de 1990 desenvolveram pesquisas aplicadas para o uso de tecnologias da informação e comunicação e para a implantação de cursos a distância. Esta ação gerou um movimento espiral que alcançou num primeiro momento grupos de pesquisa em universidades públicas para, em seguida, promover a entrada das instituições privadas no segmento da educação a distância ${ }^{16}$.

O crescimento da educação superior a distância no Brasil têm sido exponencial. Desde seu nascedouro em 1995 na Universidade Federal do

13 Claudio Rama, La encrucijada de las tendencias de la educación superior en América Latina (Santo Domingo: UNICARIBE, 2009), 26.

P. L. Torres y Claudio Rama, "Algunas de las características dominantes de la educación a distancia en América Latina y el Caribe”, in La educación superior a distancia en América Latina y el Caribe: realidades y tendências, eds. Patrícia Lupion Torres y Claudio Rama (Palhoça: Editora da Unisul, 2010), 9-16.

14 Aprofundar em estudos realizados por Vianney, Silva e Torres, para IESALC/UNESCO: João Vianney, Elizabeth Silva y Patrícia Torres, A Universidade Virtual do Brasil (Caracas: UNESCO/Unisul, 2003); João Vianney, P. L. Torres, y Elizabeth Farias, "La Educación Superior a Distância en Brasil”, in: La Educación Superior Virtual en América Latina y el Caribe, Ed. Coleción Biblioteca de la Educación Superior (México: Asociación nacional de Universidades e Instituciones de Educación Superior, 2004), 119-153; João Vianney, P. L. Torres y Elizabeth Farias, "O Ensino Superior à Distância no Brasil" in: A educação Superior Virtual na América latina e no Caribe Ed. Patrícia Lupion Torres y João Vianney (Curitiba: Editora Champagnat, 2005), 139-179.

15 Aprofundar em estudos sobre legislação, realizados por Vianney e Torres: João Vianney y P. L. Torres, "Marcos reglamentarios de la educación a distancia en la enseñanza superior brasileña" in: El Marco Regulatorio de la Educación Superior a Distancia en América Latina y el Caribe, Ed. Marta Mena, Claudio Rama, Ángel Facundo (Colômbia: UNAD, 2008), 109-152; P. L Torres y João Vianney, La calidad de la educación a distancia y sus mecanismos de aseguramiento en Brasil" in: El aseguramiento de la calidad de la educación virtual, Ed. Claudio Rama y Julio Domínguez Granda. (Perú: Gráfica Real, 2011), 119-143.

16 João Vianney y Patricia Torres, "La educación a distância en Brasil", in: La educación superior a distância: miradas diversas desde Iberoamérica, Eds. Claudio Rama y Jose Pardo (Santo Domingo: Virtualeduca - Inteved, 2010), $15-44$. 
Mato Grosso, até o ano de 2010, observa-se o crescimento desta modalidade educacional nas instituições de ensino superior, conforme se constata na tabela a seguir:

\section{Tabela 1 - Crescimento das matrículas em cursos de graduação à distância ${ }^{17}$}

\begin{tabular}{|cccccc|}
\hline \multicolumn{5}{c}{ Crescimento das matrículas em cursos de graduação a distância } \\
\hline Ano & $\begin{array}{c}\text { Cursos } \\
\text { EAD }\end{array}$ & $\begin{array}{c}\text { Aluno } \\
\text { EAD }\end{array}$ & $\begin{array}{c}\text { Aluno } \\
\text { presencial }\end{array}$ & $\begin{array}{c}\text { Total da } \\
\text { graduação }\end{array}$ & $\begin{array}{c}\text { Participação da EAD no } \\
\text { total de matrículas }\end{array}$ \\
\hline 1995 & 01 & 352 & 1.759 .351 & 1.759 .703 & $0,02 \%$ \\
2000 & 10 & 1.682 & 2.692 .563 & 2.694 .245 & $0,06 \%$ \\
2001 & 16 & 5.359 & 3.025 .395 & 3.030 .754 & $0,17 \%$ \\
2002 & 46 & 40.714 & 3.479 .913 & 3.520 .627 & $1,15 \%$ \\
2003 & 52 & 49.911 & 3.887 .022 & 3.936 .933 & $1,26 \%$ \\
2004 & 107 & 59.611 & 4.163 .733 & 4.223 .344 & $1,41 \%$ \\
2005 & 189 & 114.642 & 4.453 .156 & 4.567 .798 & $2,57 \%$ \\
2006 & 349 & 207.206 & 4.676 .646 & 4.883 .852 & $4,24 \%$ \\
2007 & 408 & 369.766 & 4.880 .381 & 5.250 .147 & $7,04 \%$ \\
2008 & 647 & 727.961 & 5.080 .056 & 5.808 .017 & $12,53 \%$ \\
2009 & 844 & 838.125 & 5.115 .896 & 5.954 .021 & $14,10 \%$ \\
2010 & 930 & 930.179 & 5.449 .120 & 6.379 .299 & $14,60 \%$ \\
\hline
\end{tabular}

A Universidade Virtual no Brasil nasce em 1996, na Universidade Federal de Santa Catarina, em cursos de pós-graduação à distância, com o uso intensivo de videoconferência e de Internet, respectivamente, ambos com suporte em material impresso.

Nestes 17 anos, as instituições de ensino superior no Brasil que se propuseram a atuar na modalidade a distância tiveram que constituir um domínio instrumental para o uso pedagógico de diversas tecnologias, como mostra o quadro a seguir:

7 Dados retirados de pesquisa apresentada pelo professor Dilvo Ristoff, no ano de 2007 e atualizados por: P. L Torres y João Vianney, "Um olhar sobre os números da educação à distância no ensino superior brasileiro", in: Politicas de Formação do Professor: caminhos e perspectivas, Eds. Romilda Teodora Ens y Marilda Aparecida Behrens (Curitiba: Champagnat, 2011), 229-257. 


\section{Quadro 3 - Tecnologias utilizadas pelas IES brasileiras na EAD no período de 1994 a $2010^{18}$}

\begin{tabular}{|c|c|c|}
\hline \multicolumn{3}{|c|}{ Tecnologias utilizadas pelas IES brasileiras na EAD no período de 1994 a 2010} \\
\hline & Meio & Estratégia de uso desenvolvida \\
\hline 1 & TV via satélite & $\begin{array}{l}\text { Produção e transmissão de tele aulas ao vivo, com recepção } \\
\text { simultânea e cobertura para todo o território nacional. }\end{array}$ \\
\hline 2 & Vídeo aulas & $\begin{array}{l}\text { Produção de aulas pré-formatadas, para reprodução em sistema } \\
\text { broadcast em rede nacional ou para reprodução em tele salas. }\end{array}$ \\
\hline 3 & Impresso & $\begin{array}{l}\text { Desenvolvimento de abordagem conceitual e implementação } \\
\text { da mesma para o desenvolvimento e publicação de conteúdos e } \\
\text { atividades de aprendizagem para livros didáticos específicos para o } \\
\text { uso na educação a distância. }\end{array}$ \\
\hline 4 & Videoconferência & $\begin{array}{l}\text { Criação de lógica de uso educacional para sistemas bi e } \\
\text { multidirecionais de interação por áudio e vídeo, integrando múltiplos } \\
\text { espaços conectados ao vivo, para realização de aulas, conferências e } \\
\text { sessões interativas de defesas de teses, dissertações e monografias. }\end{array}$ \\
\hline 5 & Telefonia & $\begin{array}{l}\text { Uso de sistemas convencionais de telefonia para provimento de } \\
\text { atendimentos diversos aos alunos, tais como secretaria, monitoria, } \\
\text { tutoria, suporte administrativo e pedagógico. }\end{array}$ \\
\hline 6 & Internet & $\begin{array}{l}\text { Desenvolvimento de sistemas autônomos para uso como ambientes } \\
\text { virtuais de aprendizagem, criação de abordagens metodológicas para } \\
\text { o ensino-aprendizagem on-line ou off-line, webconferências e etc., } \\
\text { com a aplicação das ferramentas criadas ou adquiridas. }\end{array}$ \\
\hline 7 & Telefonia móvel & $\begin{array}{l}\text { Até o início de } 2010 \text { estavam ainda em fase embrionária os estudos } \\
\text { brasileiros para o uso educacional e aplicados à educação a distância } \\
\text { dos recursos da telefonia celular e em outros dispositivos móveis. }\end{array}$ \\
\hline
\end{tabular}

A escolha tecnológica e o projeto didático das IES brasileiras resultaram, em cinco distintos modelos de educação superior a distância no Brasil. Todos eles organizados no período de 1995 a 2010, tanto em universidades públicas quanto em universidades confessionais, privadas ou comunitárias, como mostra o quadro a seguir:

18 Vianney, João; Torres, Patrícia Lupion. La educación a distância en Brasil. In: Rama, C. e Pardo, J. La educación superior à distância: miradas diversas desde iberoamérica. (Santo Domingo: Intered, 2010), 25. 


\section{Quadro 4 - Modelos de EAD estruturados e em funcionamento no Brasil (1994 - 2008) ${ }^{19}$}

\begin{tabular}{|c|c|c|c|}
\hline \multicolumn{4}{|c|}{ Modelos de EAD estruturados e em funcionamento no Brasil (1994 - 2008) } \\
\hline & Modelo & Descrição & Instituições \\
\hline 1 & $\begin{array}{l}\text { Tele-educação } \\
\text { via satélite }\end{array}$ & $\begin{array}{l}\text { Geração e transmissão de tele-aulas com } \\
\text { recepção em franquias ou tele-salas. } \\
\text { Suporte de tutoria presencial e on-line aos } \\
\text { alunos, com entrega de material didático } \\
\text { impresso ou em meio digital (CD) ou on- } \\
\text { line, via internet. }\end{array}$ & $\begin{array}{l}\text { FTC; UNOPAR; } \\
\text { UNIDERP; COC; UNIP; } \\
\text { UNINTER; CESUMAR; } \\
\text { Estácio; UNIMEP; } \\
\text { UNISA, METODISTA; } \\
\text { CESUMAR; UNITINS- } \\
\text { EADCOm. }\end{array}$ \\
\hline 2 & $\begin{array}{l}\text { Pólos de apoio } \\
\text { presencial } \\
\text { (semipresencial) }\end{array}$ & $\begin{array}{l}\text { Atendimento aos alunos em locais com } \\
\text { infraestrutura de apoio para aulas e tutoria } \\
\text { presencial, e serviços de suporte como } \\
\text { biblioteca, laboratório de informática. } \\
\text { Uso de materiais impressos de apoio, ou } \\
\text { de conteúdos em mídia digital (CD ou } \\
\text { on-line). }\end{array}$ & $\begin{array}{l}\text { UFMT; UnB; UFAL; } \\
\text { UFPB, UDESC; UFPR; } \\
\text { UFSC; UFSM; UFOP; } \\
\text { UDESC; e as demais } \\
\text { instituições vinculadas ao } \\
\text { Programa Universidade } \\
\text { Aberta do Brasil, do } \\
\text { Ministério da Educacão. }\end{array}$ \\
\hline 3 & $\begin{array}{l}\text { Universidade } \\
\text { Virtual }\end{array}$ & $\begin{array}{l}\text { Uso intensivo de tecnologias de } \\
\text { comunicação digital para o relacionamento } \\
\text { dos tutores com os alunos, e destes entre } \\
\text { si com. Bibliotecas digitais e envio aos } \\
\text { alunos de material didático impresso } \\
\text { ou digitalizado. Os tutores atendem } \\
\text { remotamente aos alunos a partir da } \\
\text { unidade central da instituição. Os locais } \\
\text { de apoio aos alunos são utilizados apenas } \\
\text { para realização de provas. }\end{array}$ & $\begin{array}{l}\text { Univs. Católicas do PR; } \\
\text { MG; DF e RS; UNISUL; } \\
\text { FGV; AIEC; UFSC; } \\
\text { UNIFESP; UNIS; } \\
\text { NewtonPaiva; UFSCar, } \\
\text { UNIVERSO; UnB; } \\
\text { UFF; UNIFESP; UFPE; } \\
\text { ANHEMBI; Claretiano, } \\
\text { IESB. }\end{array}$ \\
\hline 4 & Vídeo-educação & $\begin{array}{l}\text { Atendimento aos alunos em vídeo-salas } \\
\text { com equipamento para reprodução de } \\
\text { aulas pré-gravadas, material didático } \\
\text { impresso como apoio às aulas em vídeo. } \\
\text { Tutoria presencial e on-line. }\end{array}$ & $\begin{array}{l}\text { ULBRA; Univ. Castelo } \\
\text { Branco; UNIASSELVI; } \\
\text { IESDE. }\end{array}$ \\
\hline 5 & Unidade Central & $\begin{array}{l}\text { Sistema onde a unidade central da } \\
\text { instituição recebe regularmente a visita } \\
\text { dos alunos para atividades presenciais de } \\
\text { práticas de laboratório. A tutoria é feita } \\
\text { de maneira remota durante o período de } \\
\text { oferta das disciplinas de base conceitual. }\end{array}$ & $\begin{array}{l}\text { Universidade Federal } \\
\text { de Lavras. Algumas } \\
\text { IES fazem uso deste } \\
\text { modelo, como a UnB } \\
\text { e a UNISUL, para } \\
\text { realizar etapas com } \\
\text { uso de laboratório em } \\
\text { determinados programas. }\end{array}$ \\
\hline
\end{tabular}

19 Vianney y Lupion, "La Educación a distância en Brasil”, 26-27. 
Vale destacar que nos diversos modelos acima apresentados as dificuldades identificadas não se encontram na questão tecnológica, ou ainda de infraestrutura, mas sim, na adequação de professores e alunos que necessitam ser capacitados, pois não basta saber "mexer no computador" e "entrar na internet", é preciso manter a motivação da comunidade acadêmica e principalmente adaptar-se a um sistema novo que funciona com outro paradigma. Esta mudança de paradigma no ensino superior, passa pela troca de uma modalidade de interação professor-aluno em hora e local predeterminados para uma modalidade mais flexível que permite ao estudante escolher de acordo com sua conveniência, como, quando e onde quer aprender. Esse mudança exige ainda, uma formação docente e discente que suplante a visão linear e passe a ter características mais integradoras, interativas e colaborativas.

\section{Colaboração e interatividade como perspectivas inovadoras para a universidade virtual}

O ensino online é definido por Harasim ${ }^{20}$ como um novo campo, um novo domínio, que contém elementos da educação presencial e da educação a distância, embora diferenciando-se destas modalidades em alguns aspectos. Na educação presencial, para que seja efetivada a colaboração, as interações entre muitos são facilitadas pelos encontros presenciais, porém dependente de tempo e de local. Já na educação a distância, há a interação de um para muitos, ou de um para um, e é independente de tempo e local, porém é dificultada a interação de muitos para muitos. O ensino online reúne a independência do local, aliada à possibilidade de interação colaborativa de muitos para muitos. $\mathrm{O}$ ensino online que utiliza a colaboração apresenta mais do que uma aprendizagem ativa e interativa: apresenta índices de comunicação mais equitativos do que as taxas de participação observadas em interações presenciais.

A estruturação do ensino online na Universidade pode conservar, inicialmente, forte influência do ensino presencial. É comum uma nova estratégia de ensino, na educação superior, não ser bem vista pelos outros professores, ou mesmo pelos alunos. Colegas professores rotulam a tentativa como "baratear o ensino" ou "facilitar a aprovação", enquanto os alu-

20 L. Harasim, "On-Line Education: A New Domain", in: Mindweave: Communication, Computers and Distance instruction, eds. Robin Mason y Anthony Kaye (Oxford: Pergamon Press, 1989), 1-2. 
nos também se queixam afirmando que "preferem aula", "o professor tem que ensinar, e não pedir trabalhos em grupo". Da mesma forma, ensinar e aprender estão vinculados a um espaço que é a escola e, mais especificamente a sala de aula. Moran ${ }^{21}$ define o peso da sala de aula como uma das dificuldades sérias na aceitação da educação online.

$\mathrm{O}$ acesso à Internet como complemento às obrigações escolares assinala o primeiro passo para a transição do modelo exclusivamente presencial, tanto para professores como para alunos, trazendo atividades online no contexto da educação presencial, mesclando as propostas, permitindo elaborar intervenções de forma híbrida, mista. Trata-se então de utilizar esta familiaridade com a mídia na direção dos propósitos educacionais. Kenski ${ }^{22}$ adverte para a necessidade da formação profissional do docente que pretende atuar na educação online.

Moran $^{23}$ complementa afirmando que na educação online, os papéis do professor multiplicam-se, diferenciam-se, e complementam-se, exigindo uma grande capacidade de adaptação e criatividade diante de novas situações, propostas e atividades. A adaptação do presencial ao virtual, delegando ao espaço midiático o tempo de acesso ao conteúdo pelos alunos, da forma que mais lhes convier, supervisionado o cronograma por meio de contatos assíncronos e retornando periodicamente ao presencial, pode ser uma das muitas maneiras de aliar as vantagens do ensino presencial com o ensino online. Contudo, estas adaptações carecem de preparo adequado do professor, visto que a ausência de um bom planejamento compromete não apenas o curso (ou disciplina) online, mas também a motivação e a credibilidade do aluno (e da instituição) na educação online como concepção metodológica. Esta transição metodológica acontece no mundo inteiro nesta primeira década do século XXI, tendo como principal característica a ampliação do papel do professor, descrito por Moran ${ }^{24}$.

21 José Manuel Moran, "Contribuiçôes para uma pedagogia da educação online”, En Educaçâo Online, Eds. Marco Silva (São Paulo: Edições Loyola, 2006), 46.

22 Vani Kenski, alerta que: "Não é possível pensar que o simples conhecimento da maneira de uso do suporte (ligar a televisão ou o vídeo ou saber usar o computador e navegar na Internet) já qualificam o professor para a utilização desses suportes de forma pedagogicamente eficiente em atividades educacionais.”, 5. Vani Kenski, "Aprendizagem mediada pela tecnologia", Revista diálogo educacional, vol. 4, No 10, (2003), 47-56.

23 Moran, "Contribuiçóes para uma pedagogia", 43.

24 Moran define como: "um papel que combina com alguns momentos do professor convencional - às vezes é importante dar uma bela aula expositiva - com um papel muito mais destacado de gerente de pesquisa, de estimulador de busca, de coordenador de resultados. É um papel de animação e coordenação muito mais flexível 
A nova atribuição profissional do professor será semelhante e ao mesmo tempo diferente, no sentido que irá considerar os saberes adquiridos ao longo de sua formação, sua experiência docente, a natureza do conhecimento a ser estruturada na nova concepção metodológica, a familiaridade com as mídias e a composição dos seus grupos de alunos, conforme enfatizado por Borba ${ }^{25}$. Silva relata sua experiência em criar e mediar um curso online. ${ }^{26}$ Amplia o conceito de disponibilizar para não apenas fornecer, e sim, oferecer múltiplas informações, ensejar múltiplos percursos e estimular os alunos a contribuírem com novas informações e melhores percursos. Mais uma vez entra em cena a atualização da formação do professor para atuar em propostas online ou híbridas, evitando a mera transposição do modelo presencial para o meio digital, sem considerar as potencialidades da interface e a demanda dos alunos.

$\mathrm{Na}$ Educação Virtual é a comunicação e a interatividade que determinam o diferencial pedagógico, o que para muitos ainda não está claro, conforme revelado por Azevedo ${ }^{27}$.

O termo interatividade é apresentado por Silva ${ }^{28}$ (2006) quando descreve detalhadamente a transição da sociedade que passa da lógica da distribuição para a lógica da comunicação. Na lógica da distribuição, o modelo educacional assumiu predominantemente o formato de transmissão dos conteúdos, sendo o professor o emissor e o aluno um receptor acrítico, um recipiente vazio. A educação bancária, combatida por Freire ${ }^{29}$, presumia um aluno que

e constante, que exige muita atenção, sensibilidade, intuição (radar ligado) e domínio tecnológico. Cada curso, cada professor vai fazer isso de forma semelhante e ao mesmo tempo diferente." Moran, "Contribuiçóes para uma pedagogia”, 46.

25 A este respeito, Borba, compartilha sua experiência citando que: "a administração de um curso online, à primeira vista, parece ser fácil, porém em sua maioria, demanda mais tempo de preparação e envolvimento do que os cursos convencionais. Como exemplo, podemos pensar na necessidade de se visitar o ambiente virtual ou sítio do curso diariamente, se possível mais que uma vez ao dia, para que os alunos sintam "respaldo" por parte do professor. Isso exige um alto grau de dedicação e tempo.” Marcelo Borba, Ana Malheiros y Rúbia Zulatto, Educação a distância online (Belo Horizonte: Autêntica, 2008), 35.

26 Silva descreve a criação e mediação de um curso online como: "o exercício de superação de um problema que emperrou a aprendizagem presencial e agora prejudica igualmente a aprendizagem online: a pedagogia da transmissão" Marco Silva, Sala de Aula interativa (Rio de Janeiro: Quarter, 2006), 53.

27 Wilson Azevedo em su libro: Panorama atual da educação a distância no Brasil cita que: "a origem desta dificuldade reside numa visão limitada do que é a Internet e do que são as novas tecnologias da informação e da comunicação. Predomina o aspecto "informação" sobre a "comunicação" na percepção de muitos. Enxerga-se muito mais as possibilidades de distribuição e organização da informação que as possibilidades de comunicação mediada por computador, especialmente de interação coletiva”.

28 Silva, Sala de Aula Interativa, 188-194.

29 Paulo Freire, Pedagogia da Autonomia: saberes necessários à prática educativa (Rio de Janeiro: Paz e Terra, 2006), 47-49. 
apenas escuta, decora, repete, conforme cita Behrens ${ }^{30}$, que não questiona e nem é orientado a produzir, aplicar o conhecimento.

Silva e Santos ${ }^{31}$ complementam que mesmo em um modelo educacional em que o professor permanece como transmissor/orientador/gestor, as novas tecnologias interativas permitem ao usuário ser o autor de sua própria organização.

A importância da interação entre alunos e professor e entre alunos é lembrada também por Palloff \& Pratt $^{32}$. Estes autores relatam que, na pesquisa por eles desenvolvida, alguns colegas sentem-se atraiçoados pelos alunos que não inserem seus comentários ou contribuições, pensam que são como aproveitadores das ideias alheias, além de resultarem insatisfeitos com o empobrecimento de sua aprendizagem. Mais adiante, Palloff \& Pratt afirmam que um passo importante para aumentar a retenção é garantir uma maior interatividade, e que para tanto, o professor deve dar o exemplo que será seguido pelos seus alunos ${ }^{33}$.

Destaca-se a importância de utilizar a convivência entre os alunos para se conseguir atingir propósitos educacionais, por meio da colaboração. A colaboração designa atividades de grupo que pretendem um objetivo em comum que se concretiza na regularidade da troca, no trabalho em conjunto, na constância da coordenação ${ }^{34}$. A educação online baseia-se, pois, em dois postulados principais: de um lado, da rejeição ao autoritarismo, à condução pedagógica com motivação hierárquica, unilateral. De outro, trata-se de concretizar uma socialização não só pela aprendizagem, mas principalmente na aprendizagem. Estes dois propósitos se organizam me-

Behrens y A. O Marilda, paradigma emergente e a prática pedagógica (Curitiba: Champagnat, 2005), 43.

Silva afirma que: "cada um pode ver, ouvir, ler, gravar, reler, enviar, receber e modificar conteúdos de mensagens entendidos como espaços de intervenção, de negociação e inacabados. Cada um experimentando nẫo mais a disjunção da emissão/recepção, mas a coautoria" Silva, "Sala de Aula", 14.

32 Palloff \& Pratt comentam que: "não importa o modelo usado, ao participar de um curso online, o aluno virtual necessita compreender que a interação é esperada. Participar de um curso online não é uma experiência de leitura apenas" Rena M. Palloff y Keith Pratt, The virtual student: a profile and guide to working with online learners (San Francisco: Jossey-Bass, 2003), 69.

33 A esse respeito, Palloff \& Pratt alertam que: "O professor deve ter três prioridades em um curso online: promover e desenvolver um senso de comunidade, manter alunos engajados com o curso e uns com o outros (interatividade), e incentivar os alunos para oferecerem continuidade, a fim de conservarem o processo de construção de comunidade." Palloff y Pratt, "The virtual student", 79.

34 Patrícia L. Torres, Laboratório On Line de Aprendizagem. Uma Proposta Crítica de Aprendizagem Colaborativa para a Educação (Florianópolis: Tese de doutorado PPGEP da UFSC, 2002), 42. 
diante um instrumento que equaciona a comunicação com tais características: tratase de uma comunicação direta, contínua, construtiva.

Também na formação docente, a colaboração online pode ser aplicada como um apoio mútuo entre seus membros, conforme experiência relatada por Borba $(2008)^{35}$ com um grupo de professores da área de matemática.

Para os alunos, a colaboração busca os elementos facilitadores que são responsáveis pela propagação da cultura popular entre os alunos, conforme pesquisado por Thousand $(2001)^{36}$, da cultura acadêmica, universitária, e procura aproveitar a interação entre os alunos, para que se atinjam as metas educacionais. Nesse modelo o aluno determina quando e onde desenvolverá seu processo de aprendizagem.

Nesta última década, foram registradas dezenas de experiências de aplicação de atividades colaborativas, presenciais e mediadas por computador, desenvolvidas na PUCPR. Destaque pode ser dado à pesquisa aplicada durante um semestre com alunos do Curso de Engenharia Elétrica, conforme descreve Siqueira ${ }^{37}$. Os alunos compareciam em sala de aula para, em grupos, encontrarem soluções para problema reais da profissão, como por exemplo, elaborar o projeto de um piso aquecido. Em uma segunda intervenção, os alunos frequentavam conteúdos disponibilizados em ambiente virtual e acessados online, com os conceitos prévios, e presencialmente realizavam atividades práticas. Em uma terceira etapa, divididos em grupos, realizavam pesquisas em base de dados, sobre conteúdos da disciplina e submetiam suas pesquisas à validação de outras equipes. As comunicações entre todos os alunos nesta

35 Borba afirma que: "os membros de um grupo colaborativo assumem papéis de protagonistas ao se tornarem atores que produzem conhecimento, que aprendem e também ensinam. Eles não se limitam a meros fornecedores de informaçóes e materiais. São diferentes vozes, posicionamentos e experiências compartilhadas que podem contribuir para a melhoria da prática docente. A colaboração entre professores demanda sinergia do grupo de forma que a produçáo de conhecimento caminhe ao lado do desenvolvimento pessoal e profissional de seus membros." Marcelo Borba y Jussara Araujo, Pesquisa qualitativa em Educaçáo Matemática (Belo Horizonte: Autêntica, 2006), 31.

36 Thousand apresenta as formas vivenciadas por seus alunos na resolução de conflitos gerados pelas diferentes bagagens culturais, e conclui afirmando que a comunicação é a mais indicada, evitando o confronto, mantendo o respeito e buscando o entendimento nas atividades colaborativas. Jacqueline S. Thousand, Richard Villa y Ann Nevin, Creativity and Collaborative Learning (Baltimore: Paul Brookes, 2001), 279.

37 Siqueira y Lilia Maria Marques, A metodologia de aprendizagem colaborativa no Programa de Aprendizagem de Eletricidade no Curso de Engenharia Elétrica (Curitiba: Dissertação de Mestrado: Pontifícia Universidade Católica do Paraná, 2003), 36-39. 
atividade foram 100\% mediadas pelo ambiente virtual da Universidade, permitindo aos mesmos a vivência de aprendizagem colaborativa online.

Para realizar esta pesquisa, Siqueira desenvolveu estudo preliminar prospectando as características de cada espaço de aprendizagem dentro da Universidade (salas de aula, laboratórios de informática, salas de projeção, laboratórios de experimentos, biblioteca) e as atividades colaborativas que seriam aplicadas ${ }^{38}$. Outra pesquisa relevante foi relatada por Valaski ${ }^{39}$, que em sua dissertação de Mestrado, formatou e aplicou a colaboração junto aos alunos do curso de Desenho Industrial, na PUCPR, com a criação colaborativa de uma página web com conceitos relacionados à realidade da profissão. Os relatos conclusivos de tais pesquisas apontam para os novos papéis desempenhados pelos alunos e pelos professores, na proposta colaborativa.

A colaboração possui pressupostos da cooperação, conforme relatado por Davidson ${ }^{40}$, em seu artigo Cooperação e Colaboração - uma perspectiva integradora. Neil Davidson, na qualidade de Presidente da International Association for the Study of Cooperation in Education (IASCE), reuniu possibilidades de utilizar as aprendizagens colaborativa e cooperativa e examinou similaridades e variações entre as mesmas. As atividades foram desenvolvidas por outros professores que relataram como estabeleceram seu plano de ação em sala de aula, destacando os atributos comuns e os que variavam em cada uma das aproximações. Como atributos comuns, Davidson elencou: atividade de aprendizagem adequada para trabalho em

38 Lilia Siqueira y Paulo Roberto Alcântara, "Modificando a atuação docente utilizando a colaboração" Revista Diálogo Educacional Vol: 4 N8 (2003), 57-69.

39 Valaski relata que: "Com o propósito de ajudar o aluno a construir um senso de colaboração profissional, fundamental à atividade do designer, procurou-se desenvolver uma metodologia em que o aluno valorizasse o processo de aprendizado e se posicionasse com seriedade frente aos estudos e novos desafios, buscando associar os temas propostos com sua futura atividade profissional, percebendo a importância da geometria na relação de construção de um adequado embasamento teórico-conceitual e prático vinculado às necessidades do mercado produtivo, aliando criatividade e competência na elaboração de projetos voltados para a pesquisa e criação de páginas da Internet, uma das áreas de atuaçáo do profissional de Programaçáo Visual.” Paulo Roberto Alcântara y Suzana Valaski, "Vivenciando a aprendizagem colaborativa em sala de aula: experiências no ensino superior", Revista Diálogo Educacional, vol. 4 № 12 (2004), 169-188.

40 Davidson conclui seu estudo afirmando que: "é útil para os professores enfatizar os cinco atributos comuns entre as abordagens cooperativa e colaborativa. Os professores podem então cuidadosamente selecionar dentre as abordagens os atributos adicionais que se encaixam em seu próprios objetivos instrucionais." Neil Davidson, "Cooperative and Collaborative Learning - An integrative Perspective" in: Creativity and Collaborative learning: a practical guide to empowering students and teachers. Editado por: Jacqueline S. Thousand, Richard A. Villa and Ann I. Nevin (Baltimore: Paul Brookes Publishing Co., 2001), 29. 
grupo; definição do tamanho do grupo; comportamento de cooperação; interdependência (frequentemente referido como interdependência positiva); registro de progressos individuais; e responsabilidade. Como atributos que variam entre as cooperação e colaboração estão: procedimento do grupo (heterogêneo, aleatório, selecionado pelo aluno, interesse comum); estruturação da interdependência (objetivos, tarefas, divisão de trabalho, recompensas); ensino explícito das habilidades de colaboração, cooperação, interpessoal, relacionamento; reflexão das habilidades sociais, acadêmicas, ou dinâmica de grupo; ajuste entre construção da turma, da equipe, da confiança ou normas de cooperação; estrutura de grupo; atenção ao status do aluno pelo professor; liderança de grupo; desenvolvimento do professor para atuar de forma colaborativa.

Em uma aprendizagem em molde colaborativo a construção coletiva do conhecimento acontece mediante uma troca constante de informações, de pontos de vista, de discussões e debates, da busca de respostas para questionamentos e resoluções de problemas ${ }^{41}$. Virtualmente ou presencialmente, a importância de utilizar a convivência entre os alunos para se conseguir atingir propósitos educacionais foi também definida por Bruffee $^{42}$, há mais de 15 anos, como uma estratégia potencializadora da aprendizagem. Também Dillenbourg em 1999 enfatizou a expressão "junta” quando elaborou sua definição de aprendizagem colaborativa ${ }^{43}$, ressaltando a importância da interação, corroborando o pensamento de Bruffee.

A troca de papéis e a negociação são fundamentais em alguns modelos de atividade colaborativa, o que faz com que Dillenbourg ${ }^{44}$ (2000), Torres $^{45}$

${ }^{41}$ Patricia Lupion Torres y Lola: "A collaborative Learning Approach Using Concept Maps" in: Handbook of Research on Collaborative Learning Using Concept Mapping, eds. Patricia Lupion Torres, Marriott, y Rita de Cássia Veiga (New York: Information Science Reference, 2009), 1-12.

42 Bruffee afirma que: "Embora aprendemos muito lendo, aprendemos mais ainda quando dizemos uns aos outros o que lemos. Cada um de nós começa a mudar e descobrimos que força transformadora poderosa é a influência de uns em relação aos outros.” K. Bruffee, Collaborative Learning (Baltimore: Johns Hopkins, 1999), 9.

43 Dillenbourg afirma que: "A mais ampla (porém insatisfatória) definiçâo de aprendizagem colaborativa, é que esta é uma situação na qual duas ou mais pessoas aprendem ou tentam aprender algo juntas”. P. Dillenbourg, “¿What do you mean by collaborative learning?", em Collaborative Learning: Cognitive and Computational Approaches, eds. P. Dillenbourg (Oxford : Elsevier, 1999), 1-19.

44 Pierre Dillenbourg, Learning in the New Millennium: Building new education strategies for schools. Workshop on Virtual Learning Environments (2000).

45 Patrícia L Torres, Laboratório On Line de Aprendizagem. Uma Proposta Crítica de Aprendizagem Colaborativa para a Educação (Florianópolis: Tese de doutorado PPGEP da UFSC, 2002), 1-198. 
(2002) e Marriott ${ }^{46}$ (2004) destaquem a função dos alunos como "atores" no processo. Por meio de debates e questionamentos, os "atores" trabalham com a diversidade entre eles, valorizam a liberdade - pela alternância entre o trabalho individual e colaborativo - e vivenciam a responsabilidade - pelo comprometimento com a autoria, também relatado nas pesquisas de Torres e Marriotem $2006^{47}$ e $2007^{48}$.

De forma semelhante, Roschelle ${ }^{49}$ destacou a diferença na postura dos alunos quando estão resolvendo problemas usando a colaboração, que se propõem a um engajamento mútuo, um esforço coordenado de resolver o problema juntos, diferentemente da cooperação onde cada qual é responsável por uma parte da resolução.

Para além da sala de aula, quando este ambiente colaborativo é estabelecido virtualmente, uma rede de aprendizagem é estabelecida.Harasim ${ }^{50}$ define rede de aprendizagem como uma possibilidade dos educadores criarem ambientes de aprendizagem eficazes e colaborativos, onde professores e alunos constroem, juntos, o entendimento relacionado a um conceito em particular.

\section{CONSIDERAÇÕES}

A educação online, portanto, implicaria uma proposta pedagógica caracterizada pela: participação ativa do aluno no processo de aprendizagem; mediação da aprendizagem feita por professores e tutores; construção coletiva do conhecimento, que emerge da troca entre pares, das atividades práticas dos alunos, de suas reflexões, de seus debates e questionamentos;

46 Marriott, Rita de Cassia Veiga, Do LOLA - Laboratório on-line de Aprendizagem ao LAPLI - Laboratório de Aprendizagem de línguas: uma proposta metodológica para o ensino semi-presencial em ambiente virtual. (Curitiba: Dissertação de Mestrado do Programa de Pós-graduação em Educação da Pontifícia Universidade Católica do Paraná - PUCPR, 2004), 33-90.

47 P. L. Torres, Marriot, "A Aprendizagem Colaborativa no Laboratório on line de Aprendizagem (LOLA)”, in: Práticas Pedagógicas e Tecnologias Digitais, eds., Lynn Alves Edmea Santos (Rio de Janeiro: E-papers, 2006), 161181.

48 P. L. Torres y Rita de Cassia Veiga Marriot, "The LOLA strategy and e-learning knowledge management" in: Handbook of Research on Instructional Systems and Technology, eds. Kidd Terry T. y Song Holim (New York: Information Science Reference, 2007), 653-669.

49 J. Roschelle, y S.D. "Teasley, The construction of shared knowledge in collaborative problem solving" en: Computer-Supported Collaboraive Learning, eds. C.E. O’Malley (Berlin: Srpinger Verlag, 1995), 69-197.

50 Linda Harasim, et al., Redes de aprendizagem: um guia para ensino e aprendizagem online (São Paulo: SENEC, 2005), 29. 
interatividade entre os diversos atores que atuam no processo; estimulação dos processos de expressão e comunicação; flexibilização dos papéis no processo das comunicações e das relações a fim de permitir a construção coletiva do saber.

É também por meio da interação e da comunicação que se torna possível a superação de uma das grandes barreiras do EAD tradicional, a da manutenção da motivação do estudante. Com a internet, é possível superar a sensação de isolamento, quase sempre vivenciada por alunos a distância. Por meio da comunicação entre os diversos membros de uma "turma virtual", o aluno passa a vivenciar um sentimento de pertença, de sentir-se parte, que somente acontece em função da comunicação. Desta forma, a interatividade modifica a natureza e a qualidade da aprendizagem, sendo assim fundamental para garantir uma educação virtual de qualidade.

\section{REFERÊNCIAS}

Azevedo, Wilson. A vanguarda (tecnológica) do atraso (pedagógico): impressões de um educador on line a partir do uso de ferramentas de courseware. Rio de Janeiro: Aquifolium Educacional, 2003. http:/ / www.aquifolium.com.br/educacional/artigos/vanguarda.html.

Azevedo, Wilson. Panorama atual da educação a distância no Brasil. Rio de Janeiro: Aquifolium Educacional, 2003. http://www.aquifolium.com.br/educacional/artigos/panoread.html.

Behrens, Marilda A. O paradigma emergente e a prática pedagógica. Curitiba: Champagnat, 2005.

Borba Malheiros, Ana, \& Rúbia Zulatto. Educação a distância online. Belo Horizonte: Autêntica, 2008.

Bruffee, Kenneth. Collaborative Learning. Baltimore: Johns Hopkins, 1999.

Cunha Filho, P. C., André neves e Romulo Pinto. "O Projeto Virtus e a Construção de Ambientes Virtuais de Estudo Cooperativo". In: Educação a distancia no Brasil na era da internet, editado por Carmen Maia. São Paulo: Anhembi Morumbi, 2000, 53-72.

Davies, David. "Hacia una sociedad que aprende", en Organizaciones que aprenden y formación virtual, editado por R., D. Davies y E. Sandelands. Barcelona: EDIUOC, 2002,1.

Davidson, Neil. "Cooperative and Collaborative Learning - An integrative Perspective", in Creativity and Collaborative learning: a practical guide to empowering students and teachers, editado por Jacqueline S. Thousand, Richard A. Villa and Ann I. Nevin. Baltimore: Paul Brookes Publishing Co., 2001, 13-30.

Dillenbourg Pierre. ¿What do you mean by collaborative learning? En: Collaborative Learning: Cognitive and Computational Approaches, editado por P. Dillenbourg. Oxford: Elsevier, 1999, 1-19. 
Dillenbourg, Pierre. Learning in the New Millennium: Building new education strategies for schools. Workshop on Virtual Learning Environments. Genebra: EUN Conference, 2000 http://tecfa.unige.ch/tecfa/publicat/dil-papers-2/dil.7.5.18.pdf.

Freire, Paulo. Pedagogia da Autonomia: saberes necessários à prática educativa. $34^{a}$ ed. Rio de Janeiro: Paz e Terra, 2006, 47-49.

Kenski, Vani. "Aprendizagem mediada pela tecnologia". Revista diálogo educacional, vol: $4 \mathrm{~N}^{\circ}$ 13 (2003): 47-56.

Harasim, Linda. "On-Line Education: A New Domain”. In: Communication, Computers and Distance instruction, editado por Robin Mason yAnthony Kaye. Mindweave: Oxford: Pergamon Press, 1989, 1-2.

Harasim, Linda, Lucio Teles, Murray Turoff, y Starr Hiltz. Redes de aprendizagem: um guia para ensino e aprendizagem online. São Paulo: SENAC São Paulo, 2005,29.

Marriott, Rita de Cassia Veiga. "Do LOLA - Laboratório on-line de Aprendizagem ao LAPLI - Laboratório de Aprendizagem de linguas: uma proposta metodológica para o ensino semi-presencial em ambiente virtual”. Dissertação de Mestrado do Programa de Pós-graduação em Educação da Pontifícia Universidade Católica do Paraná - PUCPR, 2004.

Moran, José Manuel. “Contribuições para uma pedagogia da educação online.” In: Educação online, editado por Marco Silva. São Paulo: Edições Loyola, 2006, 46.

Niskier, Arnaldo. Educação à distância: a tecnologia da esperança. 2ed. São Paulo: Loyola, 2000.

Palloff, Rena M, y Keith Pratt. The virtual student: a profile and guide to working with online learners. San Francisco: Jossey-Bass, 2003.

Prensky, Marc. "Digital Natives, Digital Immigrants". On the Horizon, vol. 9: No. 5, (2001):16. http://www.marcprensky.com/writing/Prensky\%2\%20Digital\%20Natives, \%20Digital\%20 Immigrants $\% 20-\% 20$ Part $1 . p d f$

Rama, Claudio. La encrucijada de las tendencias de la educación superior en América Latina. Santo Domingo: UNICARIBE, 2009.

Roschelle, J, y S. D Teasley. "The construction of shared knowledge in collaborative problem solving”. En: Computer-Supported Collaboraive Learning, editado por C.E. O’Malley. Berlin: Srpinger Verlag, 1995, 69-197.

Silva, Marco. Educașão on-line. São Paulo: Loyola, 2003.

Silva, Marco. Sala de Aula interativa. Rio de Janeiro: Quarter, 2006.

Silva, Marcos, y Edméa Santos. Avaliação de aprendizagem em educação on line: fundamentos, interfaces e dispositivos, relatos de experiência. São Paulo: Edições Loyola, 2011.

Silva, Marco. Formação de Professores para Docência Online. São Paulo: Edições Loyola, 2012.

Silvio, Jose. La virtualizacion de la universidad. Caracas: IESALC, 2000.

Simonson, M., Hanson, D., Maushak, N. J., Schlosser, C.A., Anderson, M. L. y Sorensen C. Educación a distancia: revision de su literatura". En Educación@Distanciay Diseno Instrucional, editado por Fernando Mortera. México: Ediciones Taller Abierto, 2002, 11-70. 
Siqueira, Lilia Maria Marques. A metodologia de aprendizagem colaborativa no Programa de Aprendizagem de Eletricidade no Curso de Engenharia Elétrica. Curitiba: Dissertação de Mestrado: Pontifícia Universidade Católica do Paraná, 2003.

Siqueira, Lilia Maria Marques, y Paulo Roberto Alcântara. "Modificando a atuação docente utilizando a colaboração". Revista Diálogo Educacional, Vol: 4, № 8 (2003): 57-69.

Siqueira, Lilia Maria Marques, Paulo Roberto Alcântara, y Suzana Valaski. "Vivenciando a aprendizagem colaborativa em sala de aula: experiências no ensino superior". Revista Diálogo Educacional, vol: $4 \mathrm{~N}^{\circ} 12$ (2004): 169-188.

Thousand, Jacqueline S., Richard Villa y Ann Nevin. Creativity and Collaborative Learning. Editado por Thousand, Jacqueline S., Richard Villa y Ann Nevin. Baltimore: Paul Brookes, 2001.

Torres, Patrícia L. Laboratório On Line de Aprendizagem. Uma Proposta Crítica de Aprendizagem Colaborativa para a Educação. Florianópolis: Tese de doutorado PPGEP da UFSC, 2002. http:/ / www.eps.ufsc.br.

Torres, P. L. “O Eureka e o Laboratório On Line de Aprendizagem”, in Uma Experiência de Virtualização Universitária: O Eureka na PUCPR, editado por Matos, E. Gomes. Curitiba: Champagnat, 2003, 165-188.

Torres, P, y J. Vianney. A educação superior virtual na América Latina e no Caribe. Curitiba: Champagnat, 2005.

Torres, P. L. y João Vianney. “A evolução da EAD em 2003 e 2004 no Brasil”. En A Educação Superior Virtual na América Latina e no Caribe, editado por Patrícia Lupion Torres y João Vianney. Curitiba: Editora Champagnat, 2005, 529-531.

Torres, P. L. y Rita de Cassia Veiga Marriot. "A Aprendizagem Colaborativa no Laboratório on line de Aprendizagem (LOLA)". In: Práticas Pedagógicas e Tecnologias Digitais, editado por Edmea Santos y Lynn Alves. Rio de Janeiro: E-papers, 2006, 161-181.

Torres, P. L. y Rita de Cassia Veiga Marriot. "The LOLA strategy and e-learning knowledge management". In: Handbook of Research on Instructional Systems and Technology, editado por Terry T. Kidd y Holim Song. Hershey - New York: Information Science Reference, 2007, 653-669.

Torres, Patricia Lupion. "LOLA: A collaborative Learning Approach Using Concept Maps". In: Handbook of Research on Collaborative Learning Using Concept Mapping, editado por Patricia Lupion Torres y Rita de Cássia Veiga Marriott. Hershey - New York: Information Science Reference, 2009, 1-12.

Torres, P. L. y Claudio Rama. "Algunas de las características dominantes de la educación a distancia en América Latina y el Caribe". En La educación superior a distancia en América Latina y el Caribe: realidades y tendências, editado por Patrícia Lupion Torres y Claudio Rama. Palhoça: Editora Unisul, 2010, 9-60.

Torres, P. L. y João Vianney. "La calidad de la educación a distancia y sus mecanismos de aseguramiento en Brasil", en El aseguramiento de la calidad de la educación virtual, editado por Claudio Rama y Julio Domínguez Granda. Perú: Gráfica Real, 2011, 119-143.

Torres, P. L. y João Vianney. "Um olhar sobre os números da educação à distância no ensino superior brasileiro". Em Políticas de Formação do Professor: caminhos e perspectivas, editado por 
Romilda Teodora y Marilda Aparecida Behrens. Curitiba: Champagnat, 2011, 229-257.

Vianney, João, Alvaro Lezana, Dênia Bittencourt, Jovane Azevedo, Marcelo Camelo y Marcos Pizzaro. "Laboratório de ensino a distância: um ambiente para trocas de aprendizagem". Em Educaşão a distancia no Brasil na era da internet, editado por Carmen Maia. São Paulo: Anhembi Morumbi, 2000, 39-52.

Vianney, João, P. L. Torres y Elizabeth Farias. "Universidade Virtual: um novo conceito na EAD, in ead.br. Experiências inovadoras em educação a distância no Brasil: reflexões atuais, em tempo real, editado por Carmen Maia. São Paulo: Anhembi Morumbi, 2003, 47-62.

Vianney, João, Elizabeth Silva y Torres, Patrícia. A Universidade Virtual do Brasil. Caracas: UNESCO/Unisul, 2003.

Vianney, João, P. L. Torres y Elizabeth Farias. "La Educación Superior a Distância en Brasil". Em La Educación Superior Virtual en América Latina y el Caribe, editado por Biblioteca dela Educación Superior. México: Asociación nacional de Universidades e Instituciones de Educación Superior, (2004), 119-153.

Vianney, João, P. L. Torres y Elizabeth Farias. “O Ensino Superior à Distância no Brasil”. In: A educação Superior Virtual na América latina e no Caribe, editado por Patrícia Lupion Torres y João Vianney. Curitiba: Editora Champagnat, 2005, 139-179.

Vianney, João, P. L. Torres y Marcos Silva. "Reglamentarios de la educación a distancia en la enseñanza superior brasileña", en El Marco Regulatorio de la Educación Superior a Distancia en América Latina y el Caribe, editado por Marta Mena, Claudio Rama y Ángel Facundo. Colombia: UNAD, (2008), 109-152.

Vianney, João y Patrícia Lupion Torres. "La educación a distância en Brasil". Em La educación superior a distância: miradas diversas desde Iberoamérica, editado por Claudio Rama y J. Pardo. Santo Domingo: Intered, 2010, 15-44. 


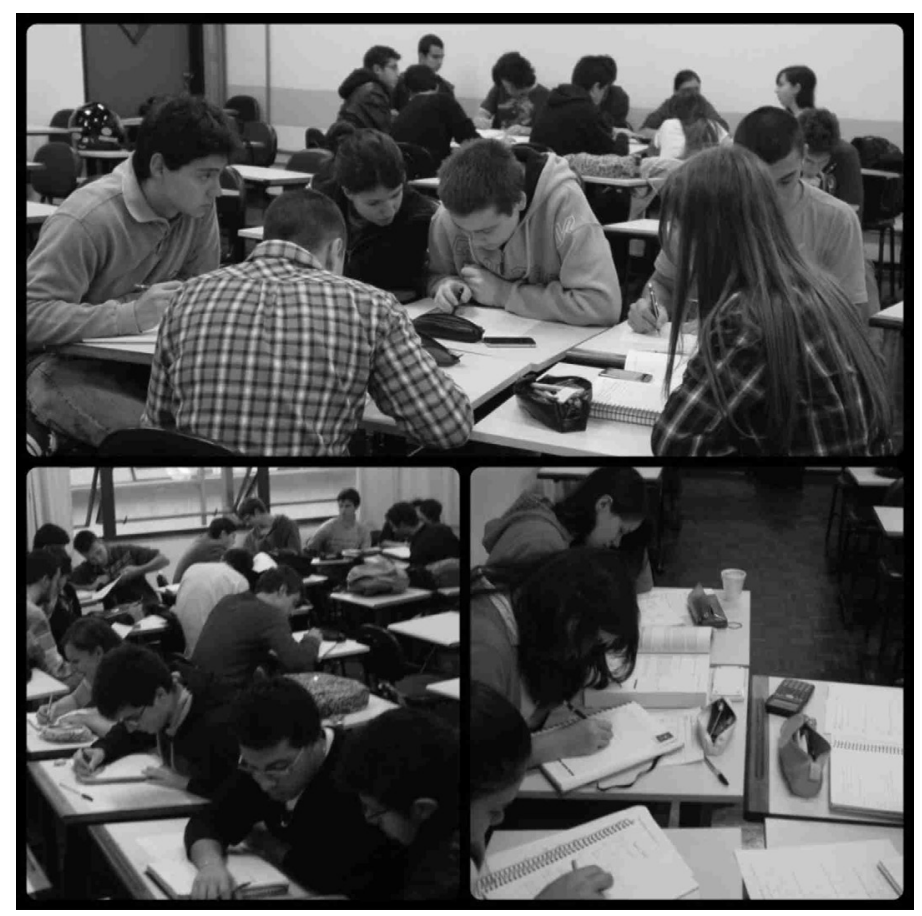

Fuente: Actividad que implica la colaboración de la Universidad Fuente: Pregrado Ingeniería - Universidad Católica de Paraná - Brasil

\begin{tabular}{l|l|} 
& \\
\hline $\begin{array}{l}\text { Lupion Torres, Patricia y Marques Siqueira, Lilia Maria. "Educação } \\
\text { virtual nas universidades: as contribuições da aprendizagem colaborativa". } \\
\text { Revista Historia de la Educación Latinoamericana. Vol. 14 No, 19, (2012): }\end{array}$ \\
\hline
\end{tabular}

